\title{
Effects of $\mathrm{Gd} / \mathrm{Ba}$ Nonstoichiometry in $\mathrm{Gd}_{1+x} \mathrm{Ba}_{2-x} \mathrm{Cu}_{3} \mathrm{O}_{7-\delta}$ on Superconducting and Magnetic Properties
}

\author{
M. Majerová, A. Cigáñ, R. Bystrický, J. Maňka, A. DvurečEnskiJ, M. Škrátek* \\ Department of Magnetometry, Institute of Measurement Science, Slovak Academy of Sciences, \\ Dúbravská cesta 9, 84104 Bratislava, Slovakia
}

\begin{abstract}
Effects of slight nonstoichiometry in $\mathrm{Gd}_{1+x} \mathrm{Ba}_{2-x} \mathrm{Cu}_{3} \mathrm{O}_{7-\delta}$ compounds on superconducting and magnetic properties were studied. The series of single-phase samples of $\mathrm{Gd}_{1+x} \mathrm{Ba}_{2-x} \mathrm{Cu}_{3} \mathrm{O}_{7-\delta}$ with composition deviation $x$ from the stoichiometric value of 0 to 0.1 and to -0.1 were synthesized by the solid-state reaction method from $\mathrm{Gd}_{2} \mathrm{O}_{3}$, $\mathrm{BaCO}_{3}$ and $\mathrm{CuO}$ precursors, sintered at the temperature of $\sim 1000^{\circ} \mathrm{C}$ in flowing oxygen and annealed at $450{ }^{\circ} \mathrm{C}$ for $24 \mathrm{~h}$.
\end{abstract}

DOI: $10.12693 /$ APhysPolA.126.354

PACS: 74.72.-h, 74.25.Ha, 75.30.Cr, 75.30.Et, 75.60.-d, 75.60.Ch, 75.60.Nt

\section{Introduction}

The $\mathrm{Gd}_{1+x} \mathrm{Ba}_{2-x} \mathrm{Cu}_{3} \mathrm{O}_{7-\delta}$ compounds belong to e.g. LRE-123 superconductors, in which LRE - light rare earth cations (where LRE $=\mathrm{Nd}, \mathrm{Sm}, \mathrm{Eu}$ and Gd) can form solid solutions with Ba ions. Among the elements, gadolinium has the highest Gennes factor, which indicates on exchange interaction of Gd ions. Moreover, between them, only the total orbital magnetic moment is zero. Thus it is interesting to study the superconducting properties [1-2] and interactions between localized magnetic spins and conduction electrons [3-5] as functions of light nonstoichiometry and magnetic field.

\section{Experimental}

The critical temperature $T_{c}(R=0)$ was determined by a standard resistance four-point method. The transition width, $\Delta T_{c}$, was characterized by the $10-90 \%$ criterion. The phase composition was studied by X-ray diffraction measurements $\left(\mathrm{CuK}_{\alpha}\right.$ radiation). AC low field magnetization at $77 \mathrm{~K}$ was measured by a compensation method using the second-order SQUID gradiometer [6]. The temperature dependences of the zero-field cooled (ZFC) and field cooled (FC) DC magnetic moment of samples were measured in the Quantum Design SQUID magnetometer MPMS XL-7 at field of $1.6 \mathrm{kA} \cdot \mathrm{m}^{-1}$ and $5.6 \mathrm{MA} \cdot \mathrm{m}^{-1}$. The corresponding temperature dependences of ZFC molar (per Gd atom) susceptibility $\chi$ at low and high field was determined and fitted to the Curie-Weiss law. The values of the Néel temperature $T_{N}$ were estimated from the maximum of molar susceptibility.

\section{Results and discussion}

From X-ray diffraction data, it can be concluded that all samples are single-phase, except the one with $x=$ -0.1 , where the observed weak peaks could be ascribed to an excess of $\mathrm{Ba}-\mathrm{Cu}-\mathrm{O}$ phase. Figure 1 shows a positive effect of Ba-excess on $T_{c}$ and $\Delta T_{c}$.

\footnotetext{
*corresponding author; e-mail: martin.skratek@savba.sk
}

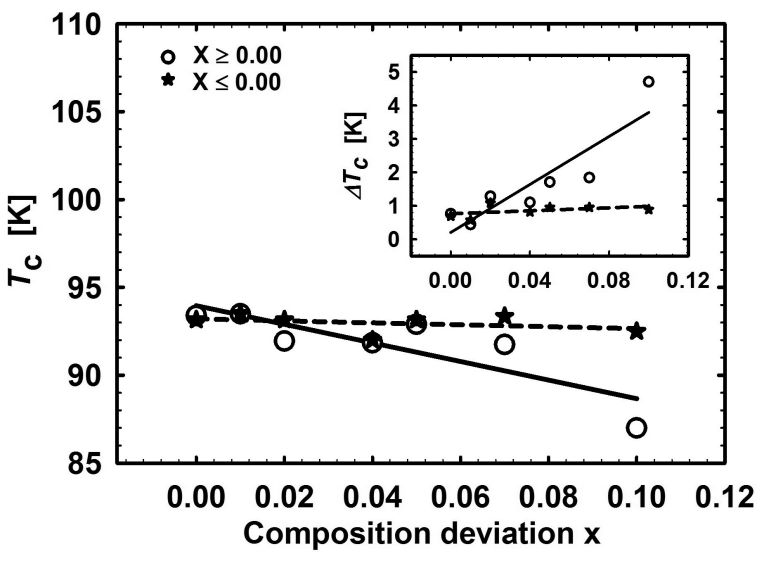

Fig. 1. $T_{c}$ vs. $x$ for $\mathrm{Gd}_{1+x} \mathrm{Ba}_{2-x} \mathrm{Cu}_{3} \mathrm{O}_{7-\delta}$. The inset shows $\Delta T_{c}$ vs. $x$.

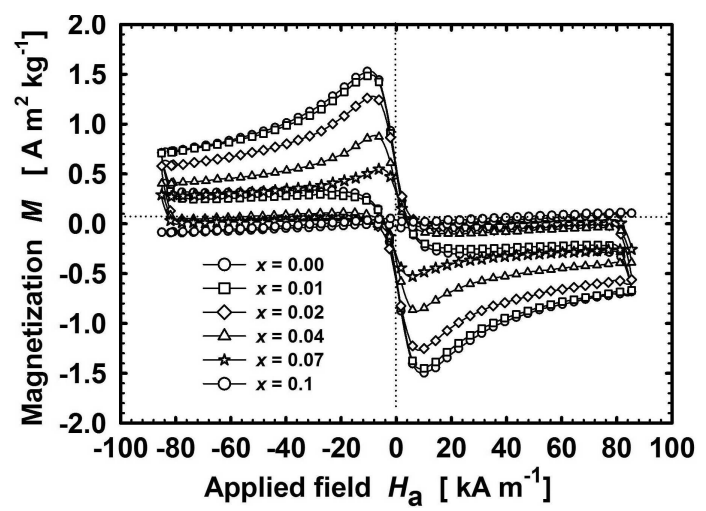

Fig. 2. $M$ vs. $H$ dependences of $\mathrm{Gd}_{1+x} \mathrm{Ba}_{2-x} \mathrm{Cu}_{3} \mathrm{O}_{7-\delta}$ at $77 \mathrm{~K}$, for $x \geq 0$.

The hysteresis curves of mass magnetization $M$ vs. applied field $H$ for $\mathrm{Gd}_{1+x} \mathrm{Ba}_{2-x} \mathrm{Cu}_{3} \mathrm{O}_{7-\delta}$ at $77 \mathrm{~K}$ and low applied field are shown in Fig. 2 and 3 . Figures 4 and 5 show ZFC molar susceptibility $\chi$ vs. $T$ for the $\mathrm{Gd}_{1+x} \mathrm{Ba}_{2-x} \mathrm{Cu}_{3} \mathrm{O}_{7-\delta}$ samples at $5.6 \mathrm{MA} \cdot \mathrm{m}^{-1}$ and $1.6 \mathrm{kA} \cdot \mathrm{m}^{-1}$, respectively. The inset in Fig. 4 shows the 


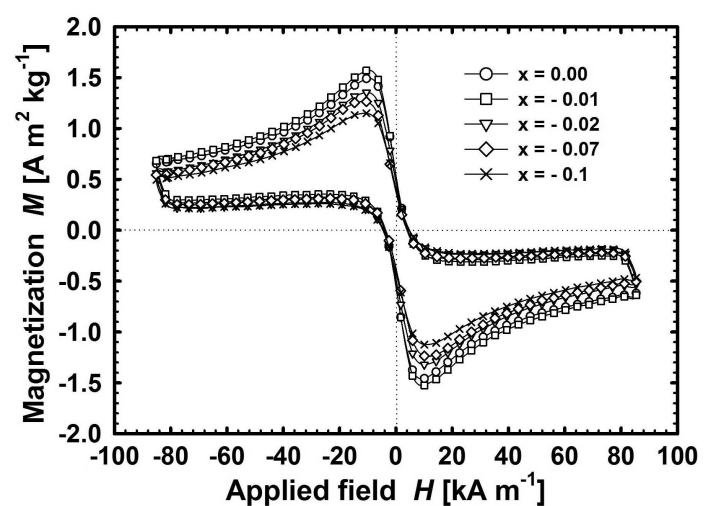

Fig. 3. $M$ vs. $H$ dependences of $\mathrm{Gd}_{1+x} \mathrm{Ba}_{2-x} \mathrm{Cu}_{3} \mathrm{O}_{7-\delta}$ at $77 \mathrm{~K}$, for $x \leq 0$.

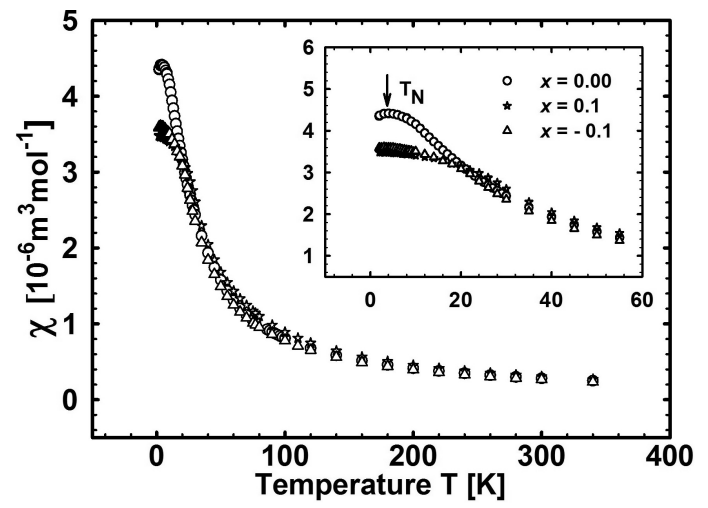

Fig. 4. ZFC $\chi$ vs. $T$ of the $\mathrm{Gd}_{1+x} \mathrm{Ba}_{2-x} \mathrm{Cu}_{3} \mathrm{O}_{7-\delta}$ at $5.6 \mathrm{MA} \cdot \mathrm{m}^{-1}$. The inset shows the enlarged view on magnetic phase transition.

enlarged view of magnetic phase transition for $x=0.00$ and the one in Fig. 5 shows $\chi^{-1}$ vs. T. The solid line represents the fit of the Curie-Weiss law. The effective magnetic moment $\mu_{e f f}$ for $x \geq 0$ increases from 7.33 to $7.72 \mu_{\mathrm{B}}$ with increasing $x$ at applied field of $5.6 \mathrm{MA} \mathrm{m}^{-1}$. The linear fit starts from the highest $T$ and ends at about $20 \mathrm{~K}$. The Weiss temperature $\Theta$ ranges from -5.76 to -

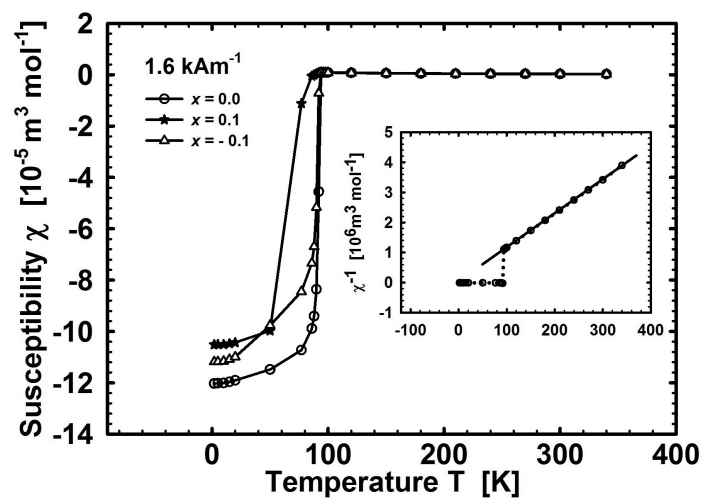

Fig. 5. ZFC $\chi$ vs. $T$ of the $\mathrm{Gd}_{1+x} \mathrm{Ba}_{2-x} \mathrm{Cu}_{3} \mathrm{O}_{7-\delta}$ at $1.6 \mathrm{kA} \cdot \mathrm{m}^{-1}$. The inset shows $\chi^{-1}$ vs. $T$ for $x=0.00$. The solid line shows the fit of the Curie-Weiss law.
$4.27 \mathrm{~K}$. For $x<0, \mu_{\text {eff }}$ shows an opposite tendency of the decrease, with increasing $x$, from 7.40 to $7.11 \mu_{\mathrm{B}}$ and $\Theta$ changes between -5.76 and $-5.26 \mathrm{~K}$. At low applied field $\mu_{e f f}$ shows the same behavior, it increases with increasing $x$ from 7.49 to $7.89 \mu_{\mathrm{B}}$ for $x \geq 0$ and decreases with $x$, from 7.50 to $7.27 \mathrm{~K}$, for $x<0$, while negative $\Theta$ is by more than an order higher, $\Theta$ changes from $56 \mathrm{~K}$ up to $-99 \mathrm{~K}$. However, the linear fit of the inverse susceptibility could not be used for $T<T_{c}$.

\section{Conclusions}

The nonstoichiometric $\mathrm{Gd}_{1+x} \mathrm{Ba}_{2-x} \mathrm{Cu}_{3} \mathrm{O}_{7-\delta}$ samples with $0.1 \leq x \leq 0.07$ show critical temperature $T_{c}$ over $92 \mathrm{~K}$ and $\Delta T_{c}$ about $1 \mathrm{~K}$ up to almost $|x| \leq 0.04$. The excess of $\mathrm{Ba}$ has a positive effect on superconducting properties at $77 \mathrm{~K}$. We have found that the change of the applied magnetic field from $5.6 \mathrm{MA} \cdot \mathrm{m}^{-1}$ to $1.6 \mathrm{kA} \cdot \mathrm{m}^{-1}$ results in a weak change of magnetic moment $\mu_{e f f}$ and over an order of magnitude increase in negative Weiss temperature $\Theta$. The $\mathrm{Gd}(\mathrm{Ba})$-excess increases (decreases) the $\mu_{e f f}$. The results indicate the role of exchange interaction of $\mathrm{Gd}$ ions and effect of structure disorder with increasing $x$. The highest Néel temperature $T_{N}=4 \mathrm{~K}$ was estimated for the stoichiometric sample.

\section{Acknowledgments}

This work was supported by the Agency of the Ministry of Education of the Slovak Republic for the Structural Funds of the EU, Operational Programme Research and Development, Project Code 26240220073 and by the project VEGA 2/0152/13.

\section{References}

[1] C. Xu, A. Hu, N. Sakai, M. Izumi, I. Hirabayashi, Physica C 417, 77 (2005).

[2] H. Shimizu, T. Tomimatsu, K. Motoya, Physica $C$ 341, 621 (2000).

[3] M. Foldeaki, M.E. Henry, G. Kalonji, R.C. O'Handley, J. Appl.Phys. 64, 5812 (1988).

[4] K. Rogacki, Physica C 387, 175 (2003).

[5] Ch. Lin, Z.-Ch. Liu, J. Lan, Phys. Rev. B 42, 2554 (1990).

[6] V. Zrubec, A. Cigáň, J. Maňka, Physica C 223, 90 (1994). 